\title{
Nanocomposite MFI-alumina and FAU-alumina Membranes: Synthesis, Characterization and Application to Paraffin Separation and $\mathrm{CO}_{2}$ Capture
}

\author{
L. Rouleau 1*, G. Pirngruber', F. Guillou', C. Barrère-Tricca', A. Omegna'2, V. Valtchev"3*, \\ M. Pera-Titus ${ }^{4}$ S. Miachon ${ }^{4}$ and J.A. Dalmon ${ }^{4}$ \\ 1 Institut français du pétrole, IFP-Lyon, BP 3, 69360 Solaize - France \\ 2 Süd-Chemie AG, Waldheimerstrasse 13, 83052 Brukmühl - Germany \\ 3 Laboratoire des Matériaux à Porosité Contrôlée (LMPC), UMR 7016 CNRS-Université de Haute Alsace, 3 rue Alfred Werner, \\ 68093 Mulhouse - France \\ 4 Université de Lyon, Institut de Recherches sur la Catalyse et l'Environnement de Lyon (IRCELYON), UMR 5256 CNRS10 - \\ Université Lyon 1, 2 Av. Albert Einstein, 69626 Villeurbanne Cedex - France \\ e-mail: loic.rouleau@ifp.fr - gerhard.pirngruber@ifp.fr - florent.guillou@ifp.fr - cecile.barrere-tricca@ifp.fr - anna.omegna@sud-chemie.com \\ valtchev@ensicaen.fr - marc.pera-titus@catalyse.cnrs.fr - sylvain.miachon@ircelyon.univ-lyon 1.fr - jean-alain.dalmon@catalyse.cnrs.fr \\ * Corresponding author \\ ** Present address : Laboratoire Catalyse \& Spectrochimie, ENSICAEN - Université de Caen - CNRS, 6 boulevard du Maréchal Juin, 14050 Caen, France
}

Résumé - Membranes nanocomposites MFI-alumine et FAU-alumine : synthèse, caractérisation \& application à la séparation de paraffines et à la capture du $\mathbf{C O}_{2}-$ Dans ce travail, nous rapportons la préparation de membranes nanocomposites MFI-alumine et FAU-alumine de haute surface $\left(24-\mathrm{cm}^{2}\right)$, thermiquement et mécaniquement résistantes, par synthèse de zéolithe dans les macropores de supports tubulaires en alumine $\alpha$. Les membranes MFI ont été préparées à partir de mélange de précurseurs de type solution claire de manière à facilement pénétrer dans les pores du support. Les membranes MFI ont été évaluées en séparation de mélanges $n$-/ $i$-butane. La fiabilité des synthèses a été améliorée par une agitation modérée. Les membranes MFI les plus sélectives ont été obtenues pour des supports avec des tailles moyennes de pores de 0,2 et 0,8 $\mu \mathrm{m}$. L'épaisseur effective de MFI a pu être réduite à moins de $10 \mu \mathrm{m}$ par imprégnation du support avec de l'eau avant la synthèse et par dilution du mélange de synthèse. La meilleure membrane MFI offre un excellent compromis entre sélectivité et perméance à $448 \mathrm{~K}$, avec des facteurs de séparation pour les mélanges $n$-butane/i-butane jusqu'à 18 et des perméances du $n$-butane en mélange aussi élevées que $0,7 \mu \mathrm{mol} \cdot \mathrm{s}^{-1} \cdot \mathrm{m}^{-2} \cdot \mathrm{Pa}^{-1}$.

Par ailleurs, une nouvelle architecture de membrane nanocomposite FAU a été obtenue par une voie de synthèse originale incluant un ensemencement in situ à partir d'un mélange refroidi de précurseur de type gel, suivi de croissance de la FAU par synthèse hydrothermale en deux étapes avec une solution claire de faible viscosité. Cette nouvelle membrane a montré des performances intéressantes en séparation de mélange équimolaire $\mathrm{CO}_{2} / \mathrm{N}_{2}$ à $323 \mathrm{~K}$, avec des facteurs de séparation $\mathrm{CO}_{2} / \mathrm{N}_{2}$ et des perméances de $\mathrm{CO}_{2}$ en mélange jusqu'à 12 et $0,4 \mu \mathrm{mol} \cdot \mathrm{s}^{-1} \cdot \mathrm{m}^{-2} \cdot \mathrm{Pa}^{-1}$, respectivement.

\footnotetext{
Abstract - Nanocomposite MFI-alumina and FAU-alumina Membranes: Synthesis, Characterization and Application to Paraffin Separation and $\mathrm{CO}_{2}$ Capture - In this work, we report the preparation of thermally and mechanically resistant high-surface (24- $\left.\mathrm{cm}^{2}\right)$ nanocomposite MFI-alumina and FAUalumina membranes by pore-plugging synthesis inside the macropores of $\alpha$-alumina multilayered
} 
tubular supports. The MFI membranes were prepared from a clear solution precursor mixture being able to easily penetrate into the pores of the support. The MFI membranes were evaluated in the separation of $n$-li-butane mixtures. The synthesis reliability was improved by mild stirring. The most selective MFI membranes were obtained for supports with mean pore sizes of 0.2 and $0.8 \mu \mathrm{m}$. The MFI effective thickness could be reduced to less than $10 \mu \mathrm{m}$ by impregnating the support with water prior to synthesis and by diluting the synthesis mixture. The best MFI membrane offered an excellent tradeoff between selectivity and permeance at $448 \mathrm{~K}$, with separation factors for equimolar $n$-butane/i-butane mixtures up to 18 and n-butane mixture permeances as high as $0.7 \mathrm{\mu mol} \cdot \mathrm{s}^{-1} \cdot \mathrm{m}^{-2} \cdot \mathrm{Pa}^{-1}$.

Furthermore, a novel nanocomposite FAU membrane architecture has been obtained by an original synthesis route including in situ seeding using a cold gel-like precursor mixture, followed by growth of the FAU material by hydrothermal synthesis in two steps using a clear solution of low viscosity. This new membrane showed interesting performance in the separation of an equimolar $\mathrm{CO}_{2} / \mathrm{N}_{2}$ mixture at $323 \mathrm{~K}$, with $\mathrm{CO}_{2} / \mathrm{N}_{2}$ separation factors and mixture $\mathrm{CO}_{2}$ permeances up to 12 and $0.4 \mu \mathrm{mol} \cdot \mathrm{s}^{-1} \cdot \mathrm{m}^{-2} \cdot \mathrm{Pa}^{-1}$, respectively.

\section{INTRODUCTION}

Zeolite membranes supported on ceramic supports have been largely proposed as promising candidates for gas separation and pervaporation applications [1-4]. Among these membranes, two families are particularly interesting for gas separation:

- MFI-type membranes for high-temperature separation of linear and branched paraffin isomers by molecular-sieving [5-8],

- FAU-type membranes for $\mathrm{CO}_{2}$ separation in pre- and post-combustion applications, as well as in the purification of natural gas and biogas. All these separations rely on the preferential $\mathrm{CO}_{2}$ adsorption on the FAU material [9-12].

Most often, the studies have focused on the synthesis of continuous, intergrown polycrystalline thin films on top of a porous support by direct or in situ hydrothermal synthesis [6]. The main limitations of this method arise from the formation of heterogeneous badly intergrown films, as well as from nutrient depletion due to preferential growth of zeolite crystals in the bulk solution [4]. These shortcomings translate in practice into the need to use several synthesis cycles to ensure the growth of well-intergrown zeolite layers.

Seeding of the support prior to hydrothermal synthesis helps improving membrane reproducibility and zeolite layer intergrowth especially when the seeds cover homogeneously the surface of support. This can be achieved in practice by means of electrostatic attachment with control of $\mathrm{pH}$ or charge [6]. Masking the support during hydrothermal synthesis helps avoiding to a certain extent zeolite crystal growth in the support porosity and promotes the synthesis of extremely thin well-intergrown polycrystalline silicalite-1 layers (about $0.5 \mu \mathrm{m}$ thickness) [7, 13]. Specific zeolite crystal orientation in the layers can be also achieved by finetuning the seed characteristics (size, shape, concentration) [8] and by hydrothermal synthesis using polycationic templates favoring preferential growth along a specific crystallographic direction [14]. This also influences the gas transport properties [15]. Orientation along the crystallographic b-axis is especially interesting in MFI synthesis, since the MFI straight channels become aligned perpendicularly to the support surface, allowing higher gas permeances.

In addition to film-like zeolite membranes, nanocomposite MFI-alumina architectures (prepared either as tubes or hollow fibres) have shown high potential to improve membrane reproducibility and the gas permeation and separation performance [15-22]. In this architecture, in contrast to a film, the active phase is embedded into the host ceramic alumina porous network via pore-plugging in situ hydrothermal synthesis (without seeding). In some cases, one heating interruption during the synthesis has been used to promote nutrient diffusion in the porous structure of the alumina support [18]. Detailed transmission electron micrographs have revealed that zeolite crystals plug neighbouring support pores [20], conferring to the material higher resistance to long-range thermal stresses during calcination and further cooling compared to supported zeolite films. This property makes nanocomposite membranes the materials of choice when large surface areas are involved. Another consequence is that mass transfer within these membranes at high temperature $(>400 \mathrm{~K})$ is kept governed by zeolite pores instead of intercrystalline openings that may appear in film-like configurations, allowing selectivity by molecular-sieving at high temperatures [15, 22-24].

Nanocomposite MFI-alumina membranes have shown their potentials in several gas and vapour separations (e.g., xylene isomer separation $[25,26]$ and ammonia recovery [27]), and combined with a catalyst in membrane reactors (e.g., $i$-butane dehydrogenation $[28,29]$ and xylene isomerization [25]). Besides, this nanocomposite configuration has also been applied to the synthesis of other membrane materials, such as Pd-ceramic [30] and MCM-41 ("LUS")-alumina [31] membranes, these latter showing high membrane quality together with high gas and water permeation performance and high structural stability. 
In this study, we present an improved protocol to prepare highly reproducible nanocomposite MFI-alumina membranes with increased gas permeances and optimal selectivities in the high-temperature separation of linear and branched paraffins ( $n$-butane $/ i$-butane). Moreover, we also present for the first time an original route for the synthesis of nanocomposite FAU-alumina membranes from a gel-like precursor solution, including a cooling step at the beginning of the synthesis to delay the gelification of the precursor solution. These membranes have been tested for $\mathrm{CO}_{2}$ capture, showing promising $\mathrm{CO}_{2} / \mathrm{N}_{2}$ separation factors.

\section{EXPERIMENTAL}

\subsection{Membrane Supports}

The supports (o.d. $10 \mathrm{~mm}$, i.d. $7 \mathrm{~mm}$, length $15 \mathrm{~cm}$, active surface $24 \mathrm{~cm}^{2}$ ) were commercial multilayered $\alpha$-alumina tubes (Membralox T1-70, Pall Exekia) with 1-cm enamelled ends. The supports included two or three layers, the pore size and thickness decreasing from the outer to the inner side (see Tab. 1). Most of the MFI and FAU membrane synthesis where carried out on support S- 0.2 , consisting of three layers with the pore size sequence 12-0.8-0.2 $\mu \mathrm{m}$ and an inner toplayer thickness of about $10 \mu \mathrm{m}$. The outer layer had a porosity of about $33 \%$, whereas the porosity of the other two layers was about $30 \%$.

\section{TABLE 1}

Textural properties of the $\alpha$-alumina supports used for membrane synthesis

\begin{tabular}{c|c|c|c|c}
\hline \multirow{2}{*}{ Support } & \multirow{2}{*}{ Membrane } & \multicolumn{3}{|c}{ Thickness $(\mu \mathrm{m}) /$ Mean pore size $(\mu \mathrm{m})$} \\
\cline { 3 - 5 } & & Layer 1 & Layer 2 & Layer 3 \\
\hline S-0.2 & MFI \& FAU & $1700 / 12$ & $15 / 0.8$ & $10 / 0.2$ \\
\hline S-0.8 & MFI & $1700 / 12$ & $15 / 0.8$ & - \\
\hline S-1.4 & MFI & $1700 / 12$ & $20 / 1.4$ & - \\
\hline
\end{tabular}

Layer $1=$ external layer;

Layer $2=$ middle or internal layer;

Layer 3 = internal layer.

Prior to synthesis, the quality of the supports was tested by a gas-liquid displacement method [20]. Only supports displaying first-bubble pressures higher than $80 \mathrm{kPa}$ using ethanol were used for membrane synthesis. Non-defective supports were then washed in an ultrasonic bath, first in ethanol and subsequently in deionised water, and finally dried at $373 \mathrm{~K}$ for $12 \mathrm{~h}$ under air flow.

\subsection{Pore-plugging Hydrothermal Synthesis}

\subsubsection{MFI-alumina Membranes}

The nanocomposite MFI-alumina membranes were prepared by in situ hydrothermal synthesis using the pore-plugging method described in previous studies [15, 20]. A precursor clear solution was prepared by dissolving Aerosil 380 pyrogenic silica (Degussa) in an aqueous tetrapropylammonium hydroxide solution (TPAOH, Sigma-Aldrich) to the final molar composition $1.0 \mathrm{SiO}_{2}$ :y TPAOH: $x \mathrm{H}_{2} \mathrm{O}$. The template (TPAOH) concentration was varied between $y=0.4-0.5$ in the first part of the study and afterwards set at 0.4. The dilution degree of the synthesis solution, $x$, was varied between 18 and 63.7 in order to modify the zeolite content and membrane thickness. The solution was aged for $72 \mathrm{~h}$ under stirring at room temperature before synthesis.

The support tube was soaked in the solution placed in a 100-mL stainless steel autoclave (Top Industrie). The synthesis mixture was poured into the autoclave to fill $75 \%$ of the total reactor volume. The autoclave was then closed and the hydrothermal treatment was performed according to three procedures:

- static and uninterrupted synthesis consisting of placing the autoclave vertically in an oven and heating it at $448 \mathrm{~K}$ for 2.5 days;

- static and interrupted synthesis consisting of placing the autoclave vertically in the oven, heating it at $448 \mathrm{~K}$ for $8 \mathrm{~h}$, subsequently cooling down to ambient temperature for $9 \mathrm{~h}$, and heating again at $448 \mathrm{~K}$ for $60 \mathrm{~h}$;

- stirred and uninterrupted synthesis involving rotation of the autoclave placed horizontally in the rotating support placed in an oven, heating to $448 \mathrm{~K}$ and stirring at moderate speed (12-30 r.p.m.) for 2.5 days.

Following the guidelines of Coronas et al. [5] and Soria and Chanaud [32], in some MFI membrane syntheses, the external surface of the tubes was wrapped with Teflon-tape and impregnated with water to limit the diffusion of the zeolite nutrients into the support.

After the synthesis, the autoclave was cooled down to room temperature, the synthesized membranes were removed, washed with deionised water until neutral $\mathrm{pH}$, and then dried at $333 \mathrm{~K}$ for $12 \mathrm{~h}$. A membrane integrity test $\left(\mathrm{N}_{2}\right.$ permeation under $40 \mathrm{kPa}$ differential pressure at room temperature) was performed at this stage to assess for the presence of large defects or cracks. The tubes showing insufficient gas tightness $\left(\mathrm{N}_{2}\right.$ permeance $\left.>10^{-12} \mathrm{~mol} \cdot \mathrm{m}^{-2} \cdot \mathrm{s}^{-1} \cdot \mathrm{Pa}^{-1}\right)$ were discarded. The selected membranes were finally calcined in a vertical oven to remove the template. Some tubes were calcined in a glass cell standing on a sintered glass disk at $793 \mathrm{~K}$ for $20 \mathrm{~h}$ under $30 \mathrm{NmL} \cdot \mathrm{min}^{-1}$ air flow using a heating rate of $0.5 \mathrm{~K} \cdot \mathrm{min}^{-1}$. The tubes were weighed before synthesis, after drying and after calcination to evaluate the zeolite and template content.

\subsubsection{FAU-alumina Membranes}

The nanocomposite FAU-alumina membranes were prepared following a three-step hydrothermal synthesis protocol. In the first step, seeds were synthesized inside the substrate pores 
by putting the support in direct contact with a cold precursor solution. In the two subsequent steps, the seeds were grown with a clear synthesis solution to promote zeolite growth in the porosity of the support top layer.

The precursor solution used for seeding had the molar composition $1 \mathrm{Al}_{2} \mathrm{O}_{3}: 7 \mathrm{SiO}_{2}: 6 \mathrm{Na}_{2} \mathrm{O}: 165 \mathrm{H}_{2} \mathrm{O}$. The solution was prepared by mixing a sodium silicate solution ( $27 \mathrm{wt} . \%$, Aldrich) and a sodium aluminate solution, and stirring until homogenization at $278 \mathrm{~K}$ to avoid gelation. The aluminate solution was prepared by dissolving sodium hydroxide (Prolabo, 98\% purity) in deionised water and adding subsequently sodium aluminate (Carlo Erba, 98\% purity) under vigorous stirring until a clear solution was obtained.

The support was dipped into the seeding synthesis mixture maintained at $278 \mathrm{~K}$ previously poured into the autoclave to fill $75 \%$ of the total reactor volume. The autoclave was closed and vacuum was applied (40 kPa) for 15 min inside of the tube to remove air from the pores of the support and favour further infiltration of the precursor. The autoclave was then closed and heated at $303 \mathrm{~K}$ for $24 \mathrm{~h}$ for precursor aging, then fixed horizontally in the rotating support in the oven and heated at $358 \mathrm{~K}$ for $24 \mathrm{~h}$ at $20 \mathrm{r}$.p.m. for hydrothermal crystallization. After the crystallization, the seeded tube was removed from the autoclave, washed thoroughly with deionized water and then dried at $373 \mathrm{~K}$ for $24 \mathrm{~h}$.

The synthesis solution used in the growth steps had the molar composition $1.0 \mathrm{Al}_{2} \mathrm{O}_{3}: 3.4 \mathrm{SiO}_{2}: 0.1 \mathrm{Na}_{2} \mathrm{O}: 400 \mathrm{H}_{2} \mathrm{O}: 2.46$ (TMA) $)_{2} \mathrm{O}$ and was prepared using a protocol based on the addition of two separate precursor solutions (A and B). Solution A was prepared by adding the appropriate amount of aluminium isopropoxide (Aldrich, 98\%) into a $25 \mathrm{wt} . \%$ solution of tetramethylammonium hydroxide (Aldrich) to obtain a clear solution. Solution B was prepared by dissolving tetraethoxisilane (Aldrich, 99\%) in deionised water and stirred for $18 \mathrm{~h}$. The two solutions were mixed at room temperature under mild stirring.

The seeded support was dipped into this synthesis mixture, filling $75 \%$ of the total reactor volume. After applying vacuum for $15 \mathrm{~min}(40 \mathrm{kPa})$ and aging at $303 \mathrm{~K}$ for $24 \mathrm{~h}$, the crystallization was carried out at $358 \mathrm{~K}$ for 21 days without stirring. The resulting material was washed with deionized water then dried at $373 \mathrm{~K}$ for $24 \mathrm{~h}$.

\subsection{Membrane Characterization}

The formation of pure MFI or FAU phases was verified by $\mathrm{X}$-ray diffraction (XRD). The XRD patterns were recorded on a Panalytical X'Pert Pro diffractometer with $\mathrm{Cu} \mathrm{K} \alpha$ radiation. The analyses were performed on zeolitic material scratched from the support top-layers. The crystallisation products formed in solution were recovered by filtration and also analysed by XRD after washing, drying and calcination.

The morphology of the zeolite crystals and the zeolite layer thickness were inspected by Scanning Electron
Microscopy (SEM) using a JEOL JSM 6340F microscope. Electron Dispersive X-ray (EDX) analysis coupled to SEM (1- $\mu \mathrm{m}$ spatial resolution) was used to evaluate the composition of micrometric-sized MFI zeolite crystals formed in the bulk solution or on the support. The composition of submicrometric MFI crystals located in smaller support macropores was evaluated by EDX analysis using a TEM microscope (FEI Tecnai 20F, spatial resolution of $30 \mathrm{~nm}$ ), after scratching the inner surface of the support. Electron Probe Micro Analysis (EPMA) was performed on MFI membranes using a JEOL JX1 8008R apparatus.

The MFI zeolite content of the tubes was measured by thermogravimetric analysis (TGA 851 Mettler). In these analyses, the tubes were heated in air $\left(25 \mathrm{NmL} \cdot \mathrm{min}^{-1}\right)$ from $298 \mathrm{~K}$ to $1273 \mathrm{~K}$ using a heating ramp of $10 \mathrm{~K} \cdot \mathrm{min}^{-1}$. The zeolite content was calculated from the weight loss between 593-793 K, which was attributed to template decomposition.

The macropore volume of the raw tubes and membranes were determined by $\mathrm{Hg}$ porosimetry using a Micromeritics Autopore porosimeter.

The acidity of the MFI membranes was evaluated by DRIFT spectroscopy (Thermo Opek Nexus spectrometer). In these experiments, $30 \mathrm{mg}$ of the nanocomposite top-layer, scratched from a tube were in situ dehydrated at $723 \mathrm{~K}$ for $10 \mathrm{~h}$ under a $30 \mathrm{NmL} \cdot \mathrm{min}^{-1}$ Ar flow. Subsequently, pyridine was adsorbed at $423 \mathrm{~K}$ by flowing $\mathrm{Ar}$ through a saturator. The spectra were recorded after adsorption of pyridine for $1 \mathrm{~h}$ to ensure that adsorption equilibrium was reached.

\subsection{Gas Permeation and Separation Tests}

The MFI membranes were first evaluated by single-gas permeation tests $\left(\mathrm{N}_{2}, \mathrm{SF}_{6}\right)$ performed at room temperature in dead-end mode to give an indication of the effective layer thickness and defect density. The target gas was fed to the retentate side of the membrane at $150 \mathrm{kPa}$, while the permeate side was kept at atmospheric pressure. The gas permeance, $\Pi\left(\mu \mathrm{mol} \cdot \mathrm{m}^{-2} \cdot \mathrm{s}^{-1} \cdot \mathrm{Pa}^{-1}\right)$, was measured using a flowmeter connected to the permeate stream of the membrane. These tests were performed on calcined membranes stored in an oven maintained at $523 \mathrm{~K}$ under primary vacuum to avoid any adsorbed species.

The MFI membranes were also tested in the separation of $n$-/i-butane mixtures at different feed composition, temperature (range 393-523 K) and sweep gas flow. Unless otherwise stated, the pressure at the feed side of the module was kept at $130-135 \mathrm{kPa}$, while the permeate was kept at atmospheric pressure. The feed mixture was fed to the inner side of the membrane. The feed flowrate was varied from 250 to $500 \mathrm{NmL} \cdot \mathrm{min}^{-1}$, in such a way that higher feed flowrates were used for the most permeable membranes. In the permeate side, He was used as sweep gas $\left(0-167 \mathrm{NmL} \cdot \mathrm{min}^{-1}\right)$ in counter-current flow. The composition of the feed, retentate 
and permeate streams was analyzed online using a Varian 3400 GC equipped with a CP Sil 5 column and a FID detector. The membranes were pre-treated in situ at $623 \mathrm{~K}$ for $4 \mathrm{~h}$ under He flow using a heating ramp of $1 \mathrm{~K} \cdot \mathrm{min}^{-1}$ to remove any adsorbed species (see ref. [33] for further details).

The FAU membranes were evaluated in the separation of $\mathrm{CO}_{2} / \mathrm{N}_{2}$ mixtures. The membranes were mounted on a counter-current gas permeation setup allowing the regulation of the feed flow rate and composition. The $\mathrm{CO}_{2}$ (Linde Gas) and $\mathrm{N}_{2}$ (Air Liquide) flowrates were both kept at $167 \mathrm{NmL} \cdot \mathrm{min}^{-1}$ to obtain an equimolar $\mathrm{CO}_{2} / \mathrm{N}_{2}$ mixture. The retentate pressure was kept in the range $130-280 \mathrm{kPa}$, while the permeate pressure was kept at atmospheric pressure. He was used as sweep gas in the permeate at a flowrate of $167 \mathrm{NmL} \cdot \mathrm{min}^{-1}$. The temperature was either kept 323 or $343 \mathrm{~K}$. The composition in the permeate and retentate streams was analysed using a Varian 3900 GC equipped with a Carbone Plot column and a FID detector. The membranes were pre-treated in situ in the same conditions as above.

The selectivity of the membranes was expressed in three different ways:

- permselectivity, as the ratio of pure gas permeances;

- separation selectivity, as the ratio of mixture permeances;

- separation factor, $S F_{i j}$, calculated as the quotient between the ratios of the molar fractions of species $i$ and $j$ in the permeate and feed sides of the membrane, i.e. $S F_{i j}=\left(y_{i} / y_{j}\right) /$ $\left(x_{i} / x_{j}\right)$.

The permeances were obtained by dividing the membrane flux by the logarithmic mean partial pressure difference between the feed/retentate and the permeate.

\section{RESULTS}

\subsection{MFI-alumina Membranes}

\subsubsection{Purity of the Zeolite Material}

Figure 1 shows the XRD patterns obtained on the material synthesized in the bulk solution, as well as in the support pores after scratching. In all cases, a pure MFI phase is formed in solution. Although the peaks corresponding to the $\alpha$-alumina phase dominate the XRD patterns in the case of the nanocomposite material, some characteristic peaks corresponding to MFI zeolite can be clearly distinguished.

\subsubsection{Weight Uptake and Membrane Integrity}

Table 2 summarizes the results obtained for gas tightness of MFI membranes synthesized by the three above stated procedures on various supports, i.e. (1) static synthesis without interruption, (2) static synthesis with a heating interruption and (3) uninterrupted synthesis by rotating the autoclave at
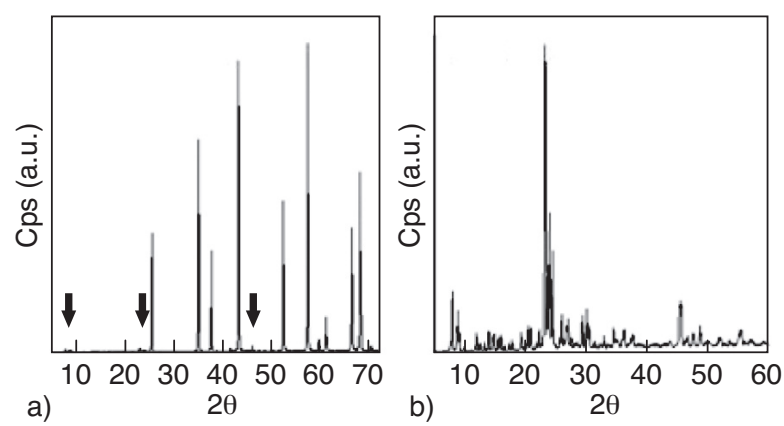

Figure 1

XRD patterns corresponding to membrane M4: a) scratched top layer, b) solid recovered in the solution. The main peaks corresponding to MFI are marked by arrows in a).

12-30 r.p.m. The "success rate" is here defined as the ratio of gas-tight membranes before calcination among the total number of synthesis following each protocol. As can be seen in Table 2, a success rate of only $18 \%$ is obtained for the membranes grown by static and uninterrupted hydrothermal synthesis on S- 0.2 supports. A heating interruption during the synthesis improves the success rate to $50 \%$ using the same supports. Finally, rotation of the autoclave during an uninterrupted synthesis ameliorates the success rate to $87 \%$ in the case of S- 0.2 supports, this value achieving $100 \%$ for the membranes synthesized in S-0.8 supports.

TABLE 2

Fraction of gas tight tubes prepared from clear solution $1.0 \mathrm{SiO}_{2}: 0.4-0.5$ TPAOH:18-63.7 $\mathrm{H}_{2} \mathrm{O}$ using three different synthesis methods

\begin{tabular}{c|c|c|c|c}
\hline Synthesis procedure & Support & $\begin{array}{c}\text { Number of } \\
\text { syntheses }\end{array}$ & $\begin{array}{c}\text { Number of } \\
\text { tight tubes }\end{array}$ & $\begin{array}{c}\text { Success } \\
\text { rate (\%) }\end{array}$ \\
\hline (1) Static and uninterrupted & S-0.2 & 11 & 2 & 18 \\
\hline (2) Static and interrupted & S-0.2 & 12 & 6 & 50 \\
\hline (3) Rotated (12-30 r.p.m.) & S-0.2 & 38 & 33 & 87 \\
and uninterrupted & S-0.5 & 11 & 9 & 80 \\
& S-0.8 & 11 & 11 & 100 \\
\hline
\end{tabular}

Table 3 summarizes the main results obtained for weight uptake after synthesis, pore-volume plugging, pure $\mathrm{N}_{2}$ and $\mathrm{SF}_{6}$ permeances and $\mathrm{N}_{2} / \mathrm{SF}_{6}$ permselectivities of some representative gas-tight MFI membranes. As expected, the weight uptake after synthesis decreases at higher dilution degree of the synthesis solution for the membranes prepared using a 12-r.p.m. rotation speed and S-0.2 supports (membranes M4M7), evolving from $3.9 \mathrm{wt} . \%$ for membrane M4 to $1.8 \mathrm{wt} . \%$ for membrane $\mathrm{M} 7$ (or from 23 to $11 \mathrm{mgMFI} / \mathrm{cm}^{2}$ of tube). In all cases, the weight uptake values obtained by weight difference match the values obtained by TGA. 
TABLE 3

Comparison of zeolite loading, room-temperature $\mathrm{N}_{2}$ and $\mathrm{SF}_{6}$ permeances $\left(\Pi \mathrm{N}_{2}\right.$ and $\Pi \mathrm{SF}$, respectively, in $\left.\mu \mathrm{mol} \cdot \mathrm{m}^{-2} \cdot \mathrm{s}^{-1} \cdot \mathrm{Pa}^{-1}\right)$ and $\mathrm{N}_{2} / \mathrm{SF}_{6}$ permselectivity of the membranes prepared in this study as a function of the synthesis procedure

\begin{tabular}{|c|c|c|c|c|c|c|c|c|c|c|}
\hline Membrane & Synthesis procedure & Support & $\begin{array}{l}\text { Rot. speed } \\
\text { (r.p.m.) }\end{array}$ & $x(-)^{\mathrm{a}}$ & $\begin{array}{l}\Delta V_{\text {macro }} \\
(\mathrm{mL} / \mathrm{g})^{\mathrm{b}}\end{array}$ & $\begin{array}{l}\Delta V m_{\mathrm{MFI}} \\
(\mathrm{wt} . \%)^{\mathrm{c}}\end{array}$ & $\begin{array}{c}\Delta V m_{\mathrm{MFI}} \text { TGA } \\
(\mathrm{wt} . \%)^{\mathrm{d}}\end{array}$ & $\Pi_{\mathrm{N}_{2}}$ & $\Pi_{\mathrm{SF}_{6}}$ & $\begin{array}{l}\mathrm{N}_{2} / \mathrm{SF}_{6} \\
\text { permsel. }\end{array}$ \\
\hline M1 & (1) Static and uninterrupted & S- -0.2 & - & 45 & - & 2.2 & - & 0.41 & 0.018 & 23 \\
\hline M2 & (2) Static and interrupted & S- 0.2 & - & 27 & - & 2.8 & - & 0.24 & 0.011 & 22 \\
\hline M3 & (2) Static and interrupted & S-0.2 & - & 63.7 & - & 1.7 & - & 0.57 & 0.019 & 30 \\
\hline M4 & (3) Rotation and uninterrupted & S-0.2 & 12 & 18 & 0.05 & 3.9 & 3.5 & 0.09 & 0.005 & 18 \\
\hline M5 & (3) Rotation and uninterrupted & S- 0.2 & 12 & 27 & - & 2.3 & - & 0.30 & 0.009 & 33 \\
\hline M6 & (3) Rotation and uninterrupted & S-0.2 & 12 & 45 & - & 1.8 & - & 0.49 & 0.015 & 33 \\
\hline M7 & (3) Rotation and uninterrupted & S- 0.2 & 12 & 63.7 & 0.03 & 1.8 & 2.1 & 0.54 & 0.017 & 32 \\
\hline M8 & (3) Rotation and uninterrupted & S-0.2 & 20 & 63.7 & - & 2.0 & - & 0.58 & 0.018 & 32 \\
\hline M9 & (3) Rotation and uninterrupted & S-0.2 & 30 & 63.7 & - & 1.8 & - & 0.60 & 0.018 & 33 \\
\hline $\mathrm{M} 10^{\mathrm{e}}$ & (3) Rotation and uninterrupted & S-0.2 & 12 & 63.7 & 0.00 & 0.8 & 0.7 & 4.36 & 0.045 & 97 \\
\hline $\mathrm{M} 11^{\mathrm{e}}$ & (3) Rotation and uninterrupted & S- -0.8 & 30 & 63.7 & 0.02 & 1.8 & 2.4 & 1.45 & 0.024 & 59 \\
\hline $\mathrm{M} 12^{\mathrm{e}}$ & (3) Rotation and uninterrupted & S-1.4 & 20 & 63.7 & 0.03 & 3.5 & - & 2.18 & 0.049 & 45 \\
\hline
\end{tabular}

a Dilution degree of the synthesis solution (mol water / mol Si);

${ }^{\mathrm{b}}$ Change of macropore volume of the support due to zeolite formation (determined by Hg porosimetry, $\pm 0.01 \mathrm{~mL} / \mathrm{g}$ );

${ }^{c}$ Determined from weight gain of the membrane after synthesis $( \pm 0.1 \%)$;

${ }^{\mathrm{d}}$ Deduced from TGA analysis on membrane after synthesis (decomposition of the template, $\pm 0.1 \%$ );

${ }^{\mathrm{e}}$ Wrapping the external surface of the support with Teflon-tape + support impregnation with water.

The decreasing trend of the weight uptake with the dilution degree at constant rotation speed is accompanied by a drastic increase of the $\mathrm{N}_{2}$ permeance from 0.09 to $0.54 \mu \mathrm{mol} \cdot \mathrm{m}^{-2} \cdot \mathrm{s}^{-1} \cdot \mathrm{Pa}^{-1}$ when increasing the dilution degree from $x=18$ (membrane M4) to $x=63.7$ (membrane M7). The pure $\mathrm{SF}_{6}$ permeance also increases with the dilution degree, but more moderately, and remains at fairly low values. The $\mathrm{N}_{2} / \mathrm{SF}_{6}$ permselectivity increases from 18 to 33 when changing the water content from $x=18$ (membrane M4) to $x=27$ (membrane M5) at a rotation speed of 12 r.p.m., remaining practically constant at 33 at higher dilution degrees.

Table 3 also shows the effect of the rotation speed on membrane quality for membranes prepared with highly diluted solutions $(x=63.7)$ on S- 0.2 supports. As can be seen, the rotation speed does not apparently exert a significant impact on the membrane properties in the range of 12-30 r.p.m. In addition, the membranes prepared by a static uninterrupted or interrupted synthesis show similar weight uptake and gas permeances after synthesis to those obtained by rotating the autoclave.

Some membranes have also been prepared to evaluate the effect of the top-layer mean pore size on the properties of nanocomposite MFI-alumina membranes prepared at a high dilution degree $(x=63.7)$ and by rotating the autoclave at 20 and 30 r.p.m. (membranes M8-M9 and M11-M12 in Tab.3). The success rate using S-0.8 and S-1.4 supports is quite high, achieving a value of $80 \%$ and $100 \%$, respectively, for a total number of 11 membrane syntheses in each case (Tab. 2). According to Table 3, the top-layer pore size does not seem to exert an effect on the weight uptake, since a value around 1.8 wt.\% has been obtained for both membranes M9 and M11 prepared at 30 r.p.m. rotation speed using S- 0.2 and S- 0.8 supports. In contrast, a remarkable difference in the weight uptake is observed when comparing membranes M8 and M12, prepared at 20-r.p.m. rotation speed using, respectively, S-0.2 and S-1.4 supports, increasing from 2.0 to $3.5 \mathrm{wt} . \%$. This latter trend is accompanied by an increase of the $\mathrm{SF}_{6}$ permeance (from 0.018 to $0.049 \mu \mathrm{mol} \cdot \mathrm{m}^{-2} \cdot \mathrm{s}^{-1} \cdot \mathrm{Pa}^{-1}$ ), reflecting an increase of non-plugged domains in the support top-layer when using S-1.4 supports. However, in the range 0.2-0.8-um mean pore size, complete plugging appears to be achieved, since the $\mathrm{SF}_{6}$ permeance is kept at low values, slightly increasing from 0.018 to $0.024 \mu \mathrm{mol} \cdot \mathrm{m}^{-2} \cdot \mathrm{s}^{-1} \cdot \mathrm{Pa}^{-1}$.

\subsubsection{Morphology of MFI-alumina Membranes: Incorporation of Al in the Zeolite Matrix}

Figure 2 shows the cross-section SEM micrographs of a raw S-0.2 support and membranes M4 and M7. As can be seen, after the synthesis, the intermediate and top layers are completely plugged by the zeolite material, while the external layer is only partially plugged. The presence of siliceous material in the internal, intermediate and external layers of both membranes has been confirmed by EPMA (see 

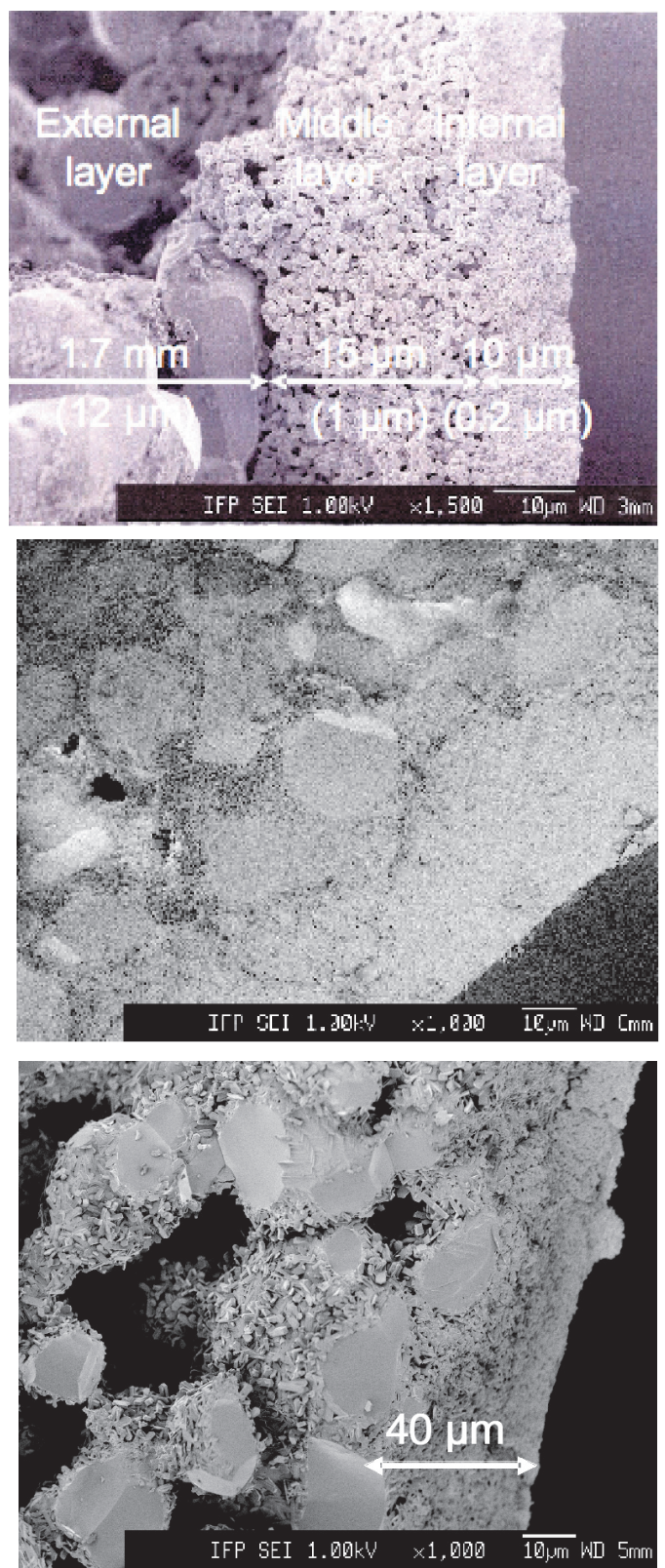

Figure 2

Cross-section SEM images of (from top to bottom): tubular tri-layered support S-0.2 (0.2 $\mu \mathrm{m}$ top-layer pore size), membrane M4 and membrane M7, both membranes formed on a S-0.2 support.

Fig. 3), the highest Si content corresponding to the former layer. In the case of membrane M7, only traces of zeolite material are observed in the external layer beyond $40-\mu \mathrm{m}$ thickness, this value being in good agreement with that obtained by SEM microscopy.

According to some EDX/SEM analyses (not shown), the micrometric zeolite crystals formed on the support display

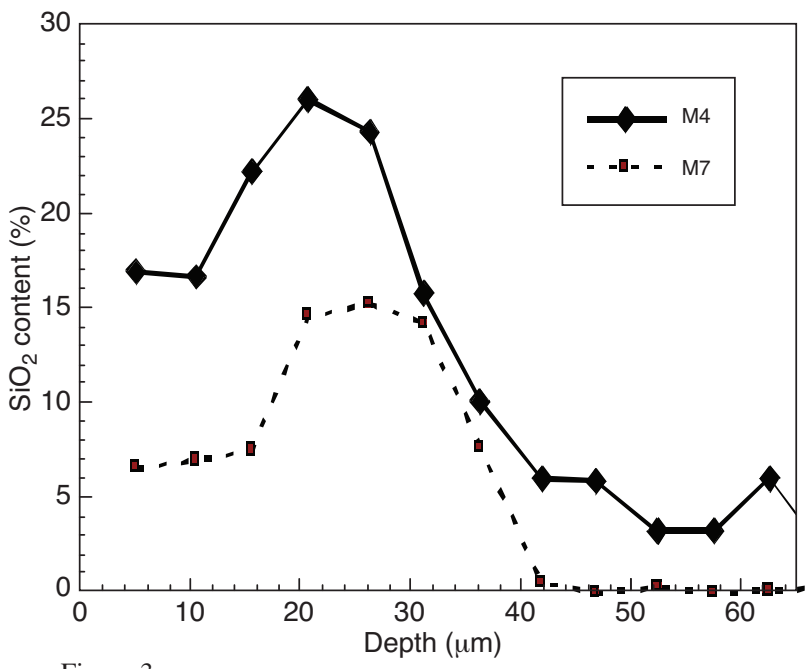

Figure 3

EPMA profiles of membranes M4 and M7.

different $\mathrm{Al}$ content as a function of the membrane thickness. In the case of membrane $\mathrm{M} 4$, the average $\mathrm{Si} / \mathrm{Al}$ ratio is close to 30 in the external layer and close to 20 on the internal face, while for membrane $\mathrm{M} 7$, these values are 40 and 80 , respectively (the average $\mathrm{Si} / \mathrm{Al}$ ratio of the crystals formed in the top layer measured by EDX-TEM for this latter membrane is close to 26).

The incorporation of $\mathrm{Al}$ into the zeolite material has also been confirmed by pyridine adsorption using DRIFT spectroscopy. Figure 4 shows two characteristic DRIFT spectra obtained on membranes M4 and M7. As can be observed, pyridine adsorption reveals the presence of Bronsted $\left(\mathrm{pyH}^{+}\right)$and Lewis (py-L) acid sites in the internal layer of the composite membrane. The presence of $\mathrm{Al}$ in the supported zeolite is attributed to the partial and local dissolution of the support due to the high alkalinity of the synthesis solution $(\mathrm{pH}=12.8)$. In contrast, only $\mathrm{Al}$ traces have been detected in the zeolite powder synthesized in bulk solution (341 and $151 \mathrm{ppm} \mathrm{Al}$, respectively, for membranes M4 and M7). The large difference in the Al content in the zeolite formed in solution and on the support reflects that $\mathrm{Al}$ incorporation in the zeolite mainly depends on its confinement in the support porosity. The $\mathrm{Al}$ content increases when the zeolite crystals are formed in smaller support macropores and decreases when these are formed far from the top layer.

\subsubsection{Effect of Support Impregnation and Wrapping}

Membrane M10 listed in Table 3 has been prepared with a highly diluted synthesis solution $(x=63.7)$, as in the case of membrane M7, but, in this case, the tubes have been previously impregnated with water and the external surface 
has been wrapped with Teflon tape. The success rate in this case appears to be improved, achieving a value of $90 \%$. A cross-section SEM micrograph of this membrane (see Fig. 5) clearly shows that, unlike membrane M7, no zeolite is formed in the intermediate and external support layers. The zeolite uptake is reduced to $0.7 \mathrm{wt} . \%$ according to the TGA results (see Tab. 3). The MFI material is only present in the pores of the $10-\mu \mathrm{m}$ top layer.

Table 3 also shows that, although membranes M7 and M10 have been synthesized using the same dilution degree, the $\mathrm{N}_{2}$ permeance of the latter is much higher, probably due to its much lower zeolite content and therefore reduced effective zeolite thickness. The $\mathrm{SF}_{6}$ permeance is higher in the case of membrane M10, but remains at a relatively low level, leading to a $\mathrm{N}_{2} / \mathrm{SF}_{6}$ permselectivity as high as 97 .
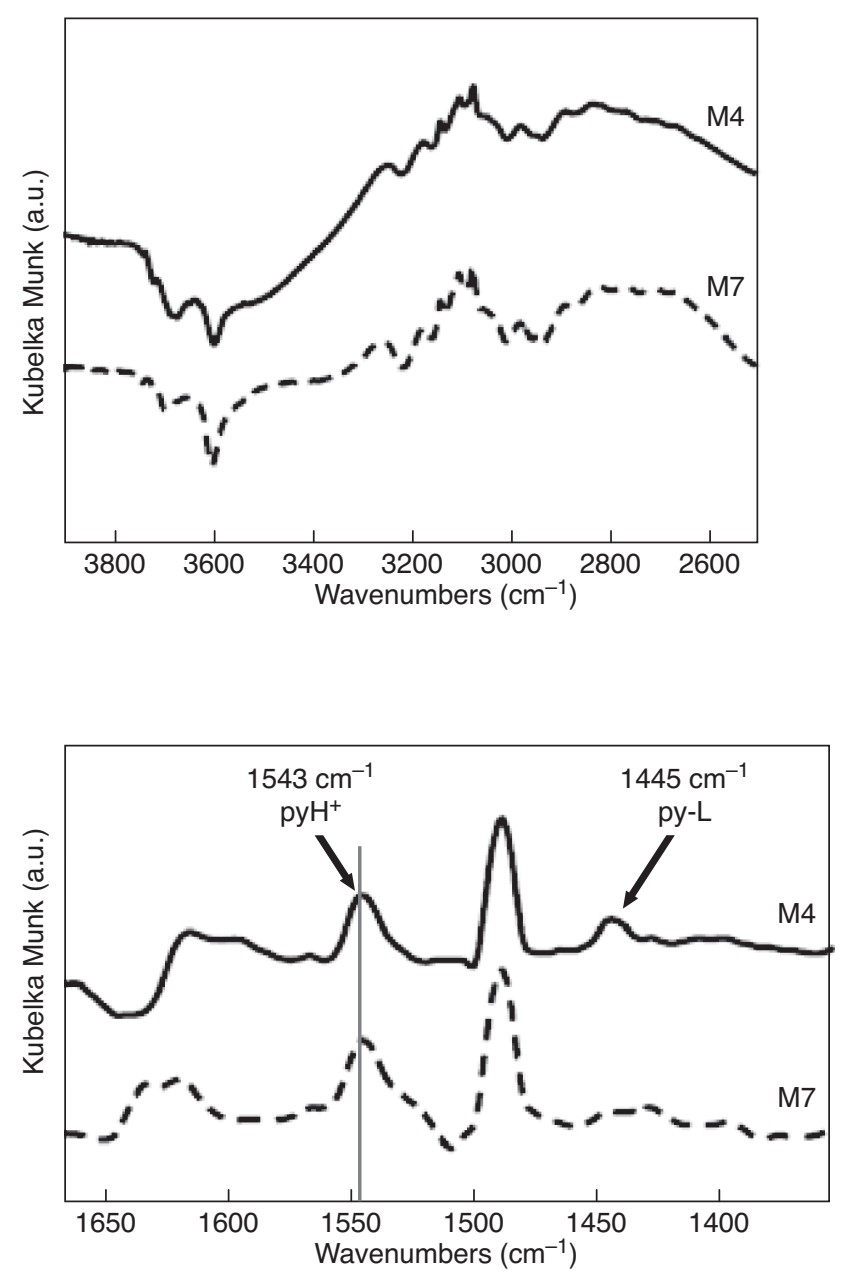

Figure 4

FTIR spectra of the scratched top layer of membranes M4 and $\mathrm{M} 7$ after pyridine adsorption at $423 \mathrm{~K}$. The symbols $\mathrm{pyH}^{+}$and py-L refer to $\mathrm{Br} \phi$ nsted and Lewis acid sites, respectively.

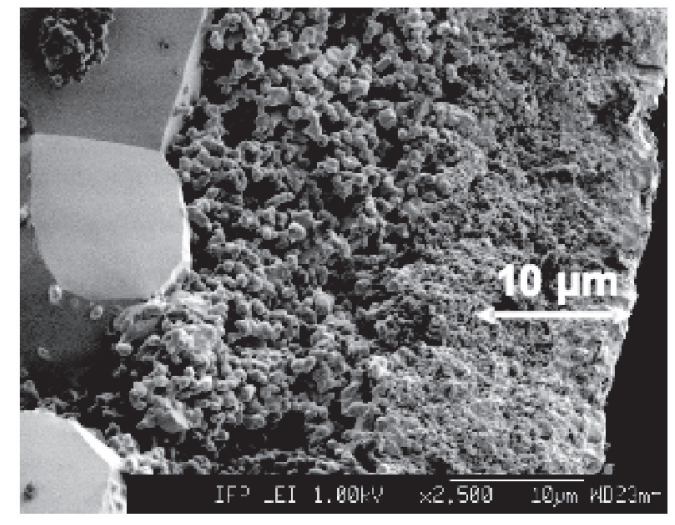

Figure 5

Cross-section SEM image of membrane M10 synthesized on a $\mathrm{S}-0.2$ support.

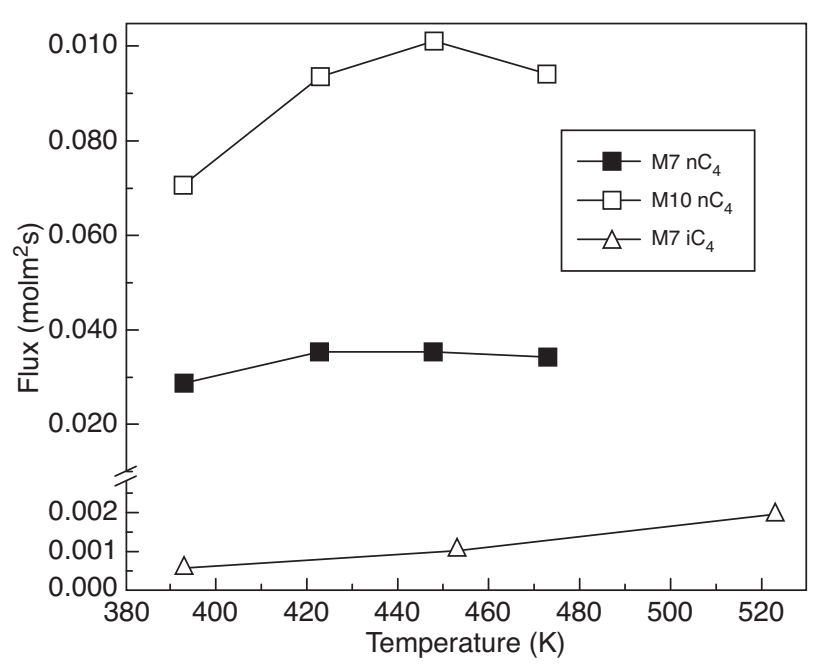

Figure 6

Flux of $n$-butane across membranes M7 and M10 and flux of $i$-butane across membrane $\mathrm{M} 7$ as a function of temperature. Conditions: retentate pressure, $300 \mathrm{kPa}$; permeate pressure, $101 \mathrm{kPa}$; sweep flow rate, $17 \mathrm{NmL} / \mathrm{min}$.

\subsubsection{Separation of $\mathrm{n}$-/i-butane Mixtures}

The single gas $\mathrm{N}_{2} / \mathrm{SF}_{6}$ permselectivity provides a rough idea of the gas permeation and separation performance of a membrane. A more realistic evaluation of the membrane performance is obtained however by assessing the temperature behaviour of the flux of a target species across the membranes in the temperature range 398-523 K. Figure 6 shows the evolution of the $n$-butane flux across membranes M7 and M10 and $i$-butane flux across membrane M7 as a function of temperature. As expected for a membrane with a 

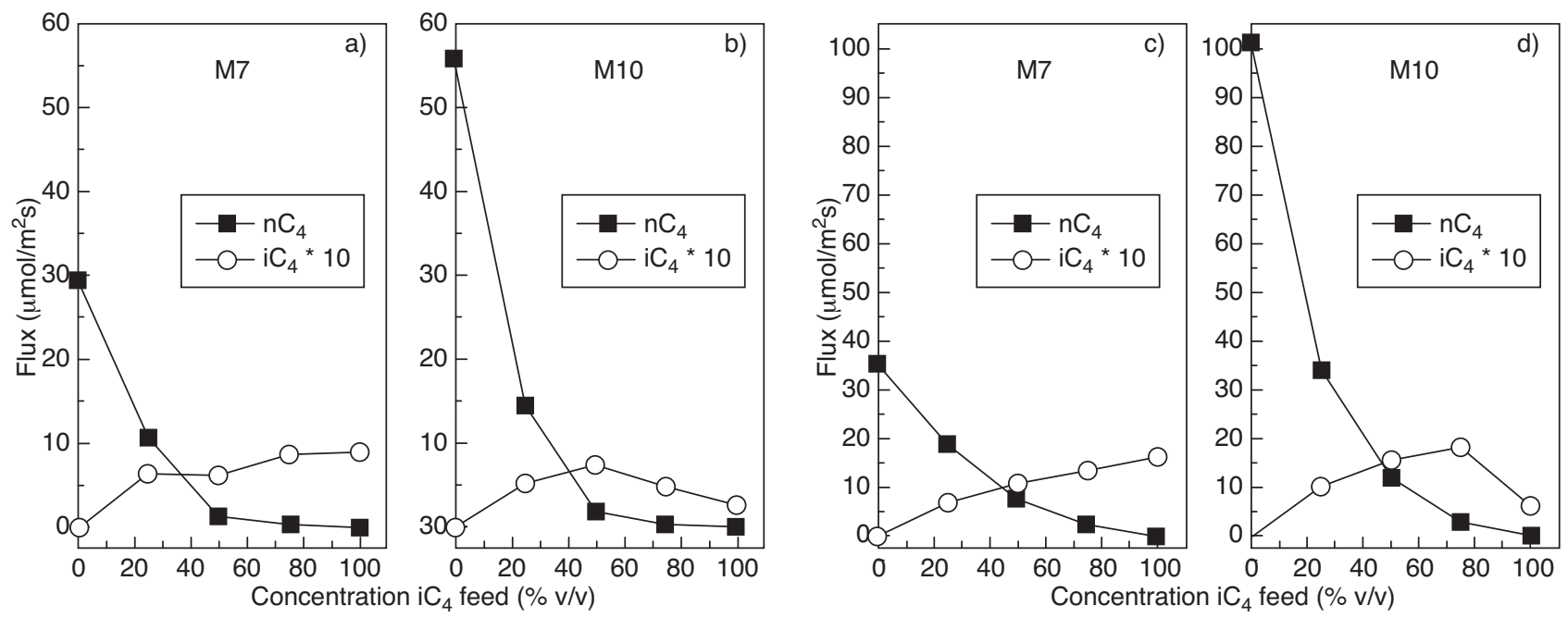

Figure 7

Flux of $n$-butane and $i$-butane (multiplied by 10) across membranes (a, c) M7 and (b, d) M10 at $448 \mathrm{~K}$ as a function of $i$-butane feed concentration in the case of no sweep flow (a, b) and using a He sweep flow rate of $17 \mathrm{NmL} / \mathrm{min}(\mathrm{c}, \mathrm{d})$. Conditions: retentate pressure, $500 \mathrm{kPa}$ $(\mathrm{a}, \mathrm{b})$ and $300 \mathrm{kPa}(\mathrm{c}, \mathrm{d})$; permeate pressure, $101 \mathrm{kPa}$.

TABLE 4

Pure and mixture $n$ - and $i$-butane permeances $\left(\Pi, \mu \mathrm{mol} \cdot \mathrm{m}^{-2} \cdot \mathrm{s}^{-1} \cdot \mathrm{Pa}^{-1}\right)$ and $n$ - $/ i$-butane mixture selectivity and Separation Factor (SF) in the separation of $75: 25 n$-/i-butane mixtures at $448 \mathrm{~K}$

Conditions: Retentate pressure, $300 \mathrm{kPa}$ : permeate pressure, $101 \mathrm{kPa}$; He sweep gas flow rate, $17 \mathrm{NmL} / \mathrm{min}$

\begin{tabular}{|c|c|c|c|c|c|c|c|}
\hline \multirow{2}{*}{ Membrane } & \multicolumn{3}{|c|}{ Pure gas permeation } & \multicolumn{4}{|c|}{ Mixture separation } \\
\hline & $\Pi_{n-\mathrm{C}_{4}}$ & $\Pi_{i-\mathrm{C}_{4}}$ & $n-\mathrm{C}_{4} / i-\mathrm{C}_{4}$ permsel. & $\Pi_{n-\mathrm{C}_{4}}$ & $\Pi_{i-\mathrm{C}_{4}}$ & Separation selectivity & $\mathrm{SF} n-\mathrm{C}_{4} / i-\mathrm{C}_{4}$ \\
\hline M4 & - & - & - & 0.10 & 0.006 & 17 & 12.6 \\
\hline M7 & 0.410 & 0.013 & 32 & 0.36 & 0.019 & 19 & 11.7 \\
\hline M10 & 1.580 & 0.005 & 316 & 0.89 & 0.028 & 32 & 14.6 \\
\hline M11 & 0.750 & 0.016 & 47 & 0.47 & 0.025 & 19 & 10.5 \\
\hline M12 & 1.025 & 0.052 & 20 & 0.50 & 0.080 & 6.25 & 3.6 \\
\hline
\end{tabular}

low amount of defects [34], the pure $n$-butane permeance reaches a maximum at about $448 \mathrm{~K}$. The pure $i$-butane flux is about 50 times lower than the value obtained for $n$-butane and increases steadily with temperature up to $523 \mathrm{~K}$. Since the diffusivity of $i$-butane is much lower than that of $n$ butane, its maximum temperature is expected to lie beyond the temperature range surveyed in this study.

A compilation of the single component $n$ - and $i$-butane gas permeance, as well as $n$-/ $i$-butane permselectivity obtained for membranes M4, M7 and M10-M12 can be found in Table 4. Table 4 also shows the performance of the five membranes in the separation of 75:25 $n$-/i-butane mixtures. The mixture $n$ and $i$-butane permeances have been measured at the temperature at which $n$-butane reaches its maximum pure flux, i.e.
$448 \mathrm{~K}$. As can be seen, membranes M4, M7, M10 and M11 are quite selective, the pure and mixture $n$-butane permeances varying linearly with the corresponding room-temperature pure $\mathrm{N}_{2}$ permeance values listed in Table 3. It is noteworthy that in all the measurements, no He counterdiffusion from the permeate to the retentate sides of the membranes is observed in the experiments carried out in the presence of a He sweep gas flow. This observation confirms the absence of a significant amount of defects in the zeolite material.

Figure 7 plots the effect of feed composition on the $n$ - $/ i$-butane separation performance of membranes M7 and M10 at $448 \mathrm{~K}$ in the presence of absence of sweep gas flow. A sharp decrease of the $n$-butane flux is observed when increasing the $i$-butane feed concentration. This does not 


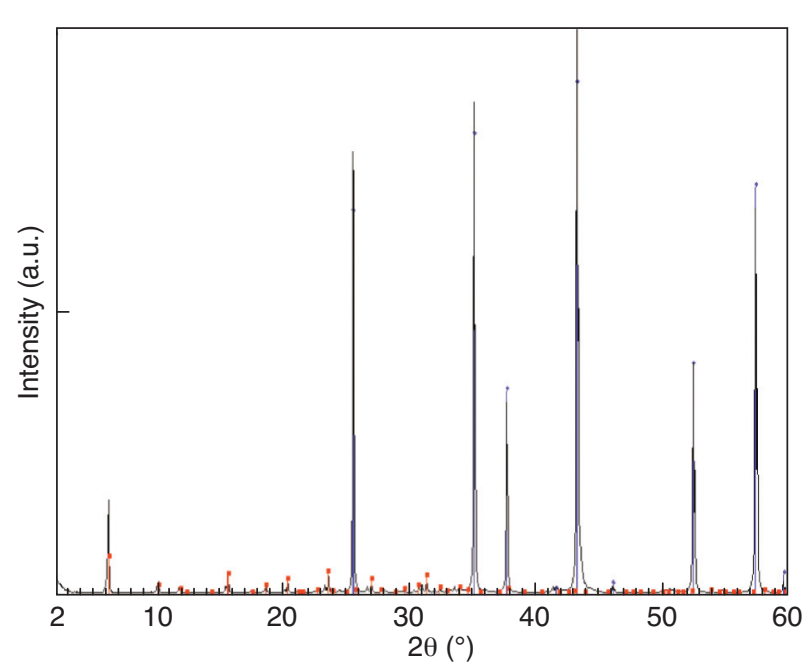

Figure 8

XRD pattern of some material scratched from the top layer of membrane M13. Red: faujasite; Blue: $\alpha-\mathrm{Al}_{2} \mathrm{O}_{3}$.

appear to be due to a hindering effect of adsorbed $i$-butane on $n$-butane diffusion, but to equalization of the $n$-butane partial pressures on both the permeate and retentate sides. The decrease is less pronounced when a sweep gas is used on the permeate side. The sweep gas increases the partial pressure gradient between the permeate and retentate and, accordingly, the driving force of $n$-butane.

\subsection{FAU-alumina Membranes}

One FAU membrane (M13) has been synthesized on a S-0.2 support following the synthesis protocol described in Section 1.2.2. The XRD patterns on some material scratched from the top layer (see Fig. 8) confirms the formation of a pure FAU zeolite phase. Moreover, the SEM images of this membrane depicted in Figure 9 clearly show the formation of zeolite crystals plugging the top-layer pores without formation of a film on top.

The FAU-alumina membrane prepared in this study has been tested in the separation of an equimolar $\mathrm{CO}_{2} / \mathrm{N}_{2}$ mixture at room temperature using $\mathrm{He}$ as sweep gas. This membrane displays a $\mathrm{CO}_{2} / \mathrm{N}_{2}$ separation factor of about 5 with a $\mathrm{CO}_{2}$ mixture permeance of $0.35 \mu \mathrm{mol} \cdot \mathrm{m}^{-2} \cdot \mathrm{s}^{-1} \cdot \mathrm{Pa}^{-1}$.

\section{DISCUSSION}

\subsection{MFI-alumina Membrane Synthesis}

\subsubsection{Membrane Integrity}

The results listed in Tables 2 and 3 indicate that rotating the autoclave during the synthesis of MFI-alumina membranes helps increasing the success rate to a value as high as $87 \%$. The success rate remains very high $(90 \%)$ when impregnating the support with water and wrapping its external surface with Teflon tape. The pore size of the support does not notably modify the success rate of MFI membrane synthesis.

Although the three synthesis methods used in this study differ in terms of success rate, the final properties of the synthesized membranes are quite similar if only successful syntheses are compared. Since rotation of the autoclave leads most often to gas-tight membranes before calcination, this method seems more convenient to prepare these membranes.

\subsubsection{Dilution of the Synthesis Solution, Support Impregnation and Wrapping}

Dilution of the synthesis solution appears to be a good strategy for reducing the amount of zeolite material grown in the alumina support, decreasing the effective zeolite layer thickness of the nanocomposite material. This translates into an increase of the pure $\mathrm{N}_{2}$ and $n$-butane permeances while keeping the permeance of bulky molecules ( $\mathrm{SF}_{6}$ and $i$-butane) almost unchanged, as can be deduced from the results listed in Tables 3 and 4.

Moreover, highly diluted solutions avoid the growth of rather large amounts of MFI material in the intermediate and external layers of the support (see Fig. 2). Pore plugging in these pores is difficult to be achieved due to their large sizes. The zeolite growth in these layers decreases the membrane flux, but does not apparently contribute to improve neither the selectivity nor the success rate. Impregnation of the support with water and wrapping its external surface with Teflon tape appear to be efficient strategies to promote zeolite growth in the top layer and therefore gas permeance (see Fig. 5).

\subsubsection{Effect of the Top-layer Pore Size on Pore Plugging}

All the membranes grown on 0.2 and $0.8-\mu \mathrm{m}$ top layer supports by rotating the autoclave and at different dilution degrees in the range $x=18-63.7$ show good quality after synthesis, achieving $n$-/ $i$-butane separation factors up to 15 (see Tab. 4). This suggests that, for these pore-size values, pore plugging is effective. However, in the case of membrane M12 prepared on a 1.4- $\mu \mathrm{m}$ top layer support, a higher $\mathrm{SF}_{6}$ permeance and a much lower $n$-/i-butane separation factor (3.6) is obtained. All these observations confirm the results already reported in a previous study [20], being attributed to a higher support reactivity in smaller macropores.

The synthesis of defect-free (plugged) membranes on larger-pore supports would probably require more concentrated synthesis solutions, higher rotation speeds and/or even several synthesis cycles. Note that, however, these strategies would involve an increase of the effective zeolite thickness, contributing therefore to a reduction of the gas permeance. 

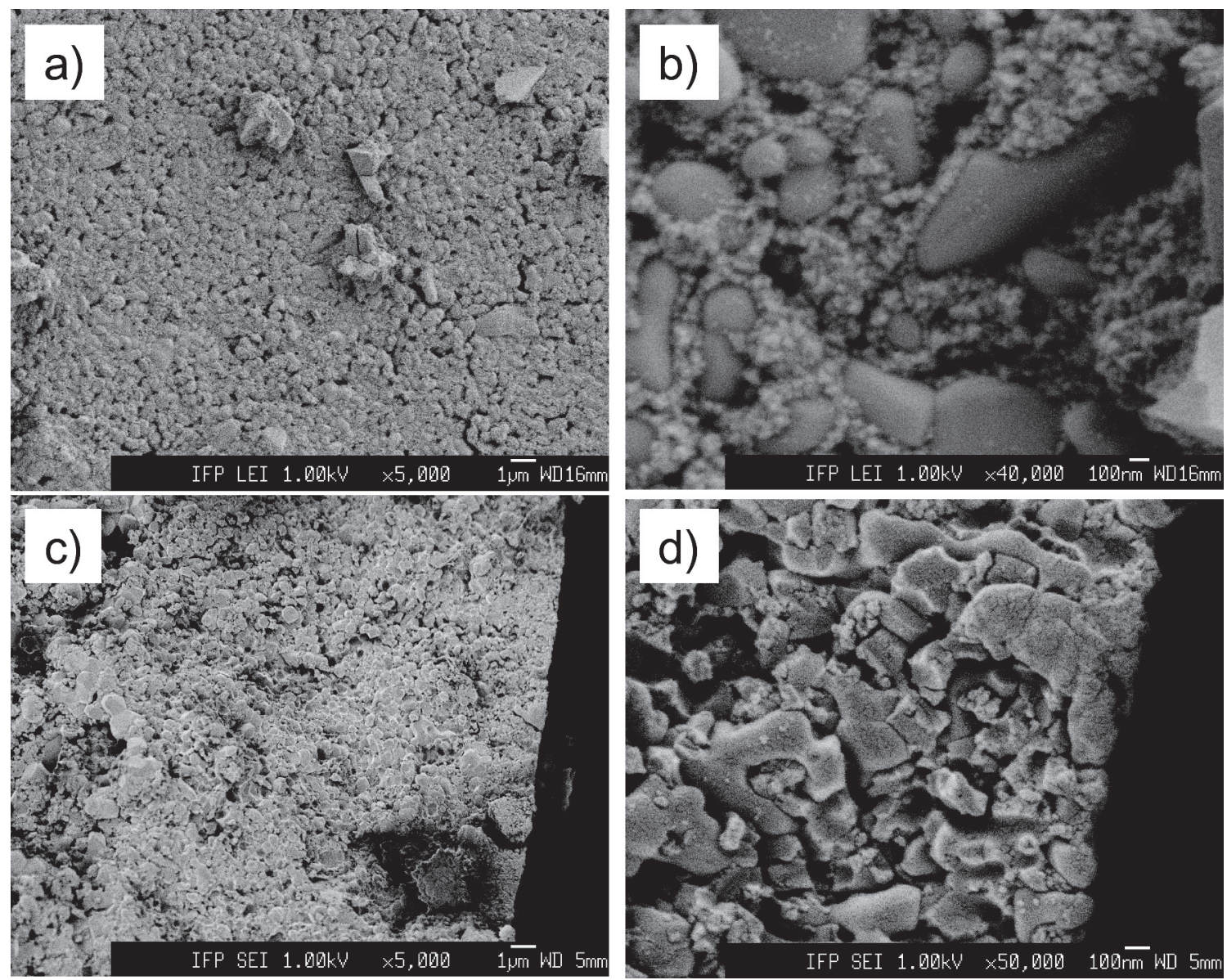

Figure 9

SEM micrographs of membrane M13: a) top view of the internal surface; b) close view of the internal surface; c) general cross-section view of the top layer; and d) close view of the top layer.

TABLE 5

Comparison of the separation performance of MFI membranes in the separation of 50:50 $\mathrm{n}$-/i-butane mixtures at high temperature

\begin{tabular}{|c|c|c|c|c|c|c|}
\hline Membrane & $\begin{array}{c}\text { Hydrothermal } \\
\text { synthesis }\end{array}$ & Support & $T(\mathrm{~K})$ & $\Pi_{\mathrm{n}-\mathrm{C} 4}$ & $\begin{array}{c}\text { Separation } \\
\text { select. }\end{array}$ & $\mathrm{SF} n-/ i-\mathrm{C}_{4}$ \\
\hline Hedlund et al. [7] $(\mathrm{Si} / \mathrm{Al}=\infty)$ & seeding + synthesis & $\alpha-\mathrm{Al}_{2} \mathrm{O}_{3} \operatorname{disk}(100 \mathrm{~nm})$ & 433 & 1.2 & - & 3 \\
\hline Coronas et al. [5] & In situ (2 steps) & $\gamma-\mathrm{Al}_{2} \mathrm{O}_{3}$ tube $(5 \mathrm{~nm})$ & 448 & $\sim 0.15$ & $\sim 5$ & - \\
\hline Coronas et al. [5] & In situ (4 steps) & $\alpha-\mathrm{Al}_{2} \mathrm{O}_{3}$ tube $(200 \mathrm{~nm})$ & 448 & 0.1 & 5 & - \\
\hline Tuan et al. [35] (Si/B = 12.5) & In situ (4 steps) & $\alpha-\mathrm{Al}_{2} \mathrm{O}_{3}$ tube $(200 \mathrm{~nm})$ & 473 & 0.16 & 60 & - \\
\hline Mori and Tomita $[36]^{\mathrm{a}}(\mathrm{Si} / \mathrm{Al}=\infty)$ & In situ & Self-supported & 473 & 0.38 & 16 & - \\
\hline M7 - this work ${ }^{b}$ & In situ (1 step) & $\alpha-\mathrm{Al}_{2} \mathrm{O}_{3}$ tube $(200 \mathrm{~nm})$ & 448 & $0.27-0.55$ & $16-31$ & $8-16$ \\
\hline M10 - this work ${ }^{\mathrm{c}}$ & In situ (1 step) & $\alpha-\mathrm{Al}_{2} \mathrm{O}_{3}$ tube $(200 \mathrm{~nm})$ & 448 & $0.40-0.73$ & $17-24$ & $8-18$ \\
\hline
\end{tabular}

a Equimolar mixture diluted in $\mathrm{N}_{2}$;

${ }^{b}$ Sweep gas flow of 17 or $83 \mathrm{NmL} / \mathrm{min}$;

${ }^{\mathrm{c}}$ Sweep gas flow of 17 or $166 \mathrm{NmL} / \mathrm{min}$. 
TABLE 6

Synthesis conditions, characteristics and performance of FAU-type membranes in $\mathrm{CO}_{2}-\mathrm{N}_{2}$ separation. Mixture permeances, separation selectivities and separation factors $\left(\mathrm{SF}_{\mathrm{CO}_{2} / \mathrm{N}_{2}}\right)$ of FAU-type membranes, in the separation of equimolar mixtures of $\mathrm{CO}_{2} / \mathrm{N}_{2}$ with He as sweep gas

\begin{tabular}{|c|c|c|c|c|c|c|c|c|}
\hline \multirow[t]{2}{*}{ Membrane } & \multirow{2}{*}{$\begin{array}{l}\text { Seeding method/ } \\
\text { seed size order }\end{array}$} & \multirow[t]{2}{*}{ Growth method } & \multirow[t]{2}{*}{ Surface $\left(\mathrm{cm}^{2}\right) /$ type } & \multirow[t]{2}{*}{$T(\mathrm{~K})$} & \multicolumn{2}{|c|}{$\begin{array}{l}\text { Mixture permeance } \\
\left(\mu \mathrm{mol} \cdot \mathrm{m}^{-2} \cdot \mathrm{Pa}^{-1} \cdot \mathrm{s}^{-1}\right)\end{array}$} & \multirow{2}{*}{$\begin{array}{l}\text { Selectivity } \\
\text { Separation }\end{array}$} & \multirow{2}{*}{$\mathrm{SF}_{\mathrm{CO}_{2} / \mathrm{N}_{2}}$} \\
\hline & & & & & $\mathrm{CO}_{2}$ & $\mathrm{~N}_{2}$ & & \\
\hline Kusakabe et al. [11] & 1 Rubbing / $\mu \mathrm{m}$ & 1 Static HS & $17.6 / \alpha-\mathrm{Al}_{2} \mathrm{O}_{3}$ tube $^{1}$ & 313 & 1.3 & 0.04 & 30 & - \\
\hline Clet et al. [12] & \multicolumn{2}{|c|}{1 seeded stirred HS / mm } & nd / $\alpha-\mathrm{Al}_{2} \mathrm{O}_{3}$ disk & 303 & 0.34 & 0.09 & 4 & - \\
\hline Cheng et al. [37] & 3 Dip coating $/ \mathrm{nm}$ & $1 \mathrm{VPT}$ & $4.5 / \alpha-\mathrm{Al}_{2} \mathrm{O}_{3}$ disk & $\begin{array}{l}298 \\
373\end{array}$ & $\begin{array}{l}0.15 \\
0.20 \\
\end{array}$ & $\begin{array}{l}0.003 \\
0.008\end{array}$ & $\begin{array}{l}54 \\
50\end{array}$ & - \\
\hline M13 - this work & 1 In-situ HS & 2 Static HS & $24 / \alpha-\mathrm{Al}_{2} \mathrm{O}_{3}$ tube & $\begin{array}{l}323 \\
343\end{array}$ & $\begin{array}{l}0.35 \\
0.36\end{array}$ & $\begin{array}{l}0.03 \\
0.05\end{array}$ & $\begin{array}{c}12 \\
7\end{array}$ & $\begin{array}{l}5.7 \\
4.2\end{array}$ \\
\hline
\end{tabular}

HS: Hydrothermal Synthesis; VPT: Vapour Phase Transformation.

${ }^{1}$ Membrane cut to $2.6 \mathrm{~cm}^{2}$ for gas permeation and separation measurements.

\subsubsection{Membrane Performance in Paraffin Separation}

The high $\mathrm{N}_{2}$ permeances and $\mathrm{N}_{2} / \mathrm{SF}_{6}$ permselectivities of the membranes listed in Table 3 reflect that, under optimized synthesis conditions (high dilution degree of the synthesis solution, rotation of the autoclave, support impregnation and wrapping), nanocomposite MFI-alumina membranes prepared by in situ hydrothermal synthesis show a good compromise between gas permeation and separation.

Table 5 compares the permeation and separation performance of the best quality MFI-alumina membranes synthesized in this study (M7 and M10) towards separation of equimolar $n$-/i-butane mixtures at high temperature (433-473 K) to some data available in the literature. In general terms, highly selective membranes show moderate permeances, whereas highly permeable membranes usually show low selectivities. The membranes prepared in this study represent a good compromise between selectivity and permeance. Their performance is quite similar to that recently reported on self-supported membranes [36]. Self-supported membranes suffer, however, from a lack of mechanical stability, being detrimental for practical applications.

\subsubsection{FAU-alumina Membrane Synthesis}

The extension of the synthesis protocol used in the preparation of nanocomposite MFI-alumina membranes to FAU-alumina membranes is not trivial. The key point in the preparation of nanocomposite MFI-alumina membranes is the use of a clear synthesis solution with a low viscosity, easy to infiltrate into the support pores. In the case of FAU-type zeolite membranes, the precursor solution gelifies very fast (within a few minutes), achieving therefore high viscosity. Therefore, the gel cannot penetrate into the support porosity, leading to the preferential formation of zeolite crystals on the top-layer when the support is put into contact with an already gelified synthesis solution.
In this study, the strategy chosen to inhibit gelification of the synthesis solution by decreasing its temperature appears to be promising to promote the infiltration of the synthesis solution into the support porosity. We have found in this study that the gelification time increases from a few minutes to $1 \mathrm{~h}$ when the synthesis solution is prepared at $278 \mathrm{~K}$ instead of room temperature. Using this strategy, a good quality nanocomposite FAU-alumina membrane has been synthesized without film formation on top of the support (see Fig. 9), the FAU material being primarily localized in the $0.2-\mu \mathrm{m}$ top layer. Table 6 shows that the performance of these membranes towards separation of $\mathrm{CO}_{2} / \mathrm{N}_{2}$ equimolar mixtures is comparable in terms on separation factor and $\mathrm{CO}_{2}$ mixture permeance to the values reported in the literature on film-like FAU ( $X$ and $Y$ ) membranes prepared by secondary growth.

\section{CONCLUSIONS}

In this study, optimized nanocomposite MFI-alumina, as well as a new nanocomposite FAU-alumina membrane, have been successfully synthesized by pore plugging synthesis in a multilayered $\alpha$-alumina tube. In each case, the MFI and FAU crystals plug support top layer macropores without formation of a film. The MFI-alumina membranes have been synthesized using a clear silicate-1 solution in a single in situ hydrothermal cycle. The MFI membrane synthesis has been optimized by combining the following strategies:

- rotation of the autoclave (12-30 r.p.m.);

- high dilution of the synthesis solution;

- water impregnation of the support and wrapping of the external surface of the support by Teflon tape;

- use of a support with smaller top-layer macropores $(0.2$ or $0.8 \mu \mathrm{m})$. 
The MFI membranes described in this work offer a good tradeoff between permeance and selectivity in the separation of linear and branched paraffins at high temperatures. The most selective nanocomposite MFI-alumina membranes represent a thin composite layer located exclusively in the $10 \mu \mathrm{m}$ internal layer of the $\alpha$-alumina support (pore size of $0.2 \mu \mathrm{m}$ ). The micrometric-sized MFI crystals are densely packed in the voids of the alumina support plugging the porosity of the inner top layer. Yet, the intercrystalline connectivity in such a composite layer is always defective. In order to compensate these defects, the thickness of the "effective" zeolite layer should be at least 10 times the crystal size. Reducing the thickness below this value is possible but will result in higher permeance through intercrystalline defects, reducing therefore the selectivity. Therefore, the potential for further gains in terms of permeance seems to be limited (unless smaller zeolite crystals and smaller support pores are used).

A nanocomposite FAU-alumina membrane has been prepared by a new synthetic approach involving in situ seeding in the top layer pores of an $\alpha$-alumina tubular support. The key point of our protocol consists of cooling down a gel-like synthesis solution before bringing it into contact with the porous alumina substrate, delaying the gelation and allowing a better infiltration of the solution into the support. Subsequent hydrothermal treatment of the seeded supports with a clear solution allows the growth of a sufficient amount of zeolite material to plug the top-layer support pores. Although the methodology here proposed is far from being optimized, this new nanocomposite FAU membrane offers a good compromise between permeance and selectivity in the separation of $\mathrm{CO}_{2} / \mathrm{N}_{2}$ equimolar mixtures. The reproducibility of this FAU membrane synthesis has not been studied in this work, but is probably better than in the preparation of film-like membranes, as already reported for MFI membranes [15-22]. Further development in the near future will focus on the reduction of useless zeolite in larger pores by impregnating and wrapping the tubes during the synthesis, and on the minimization of intercrystalline defects by optimizing the growth conditions.

\section{ACKNOWLEDGMENTS}

The authors would like to express their gratitude to E. Landrivon, from IRCELYON, for useful exchange for interrupted syntheses. The authors would like to give special thanks to Charles Leroux, Céline Lemaire, Olivier Boisier, Charlène Le Belguet for their contribution to the membrane synthesis, as well as Jean-Pierre Courcy, Jean-Pierre Rey for performing the permeation tests.

\section{REFERENCES}

1 Caro J., Noack M. (2008) Micropor. Mesopor. Mat. 115, 215.

2 Li Y., Yang W. (2008) J. Membrane Sci.316, 3.

3 Julbe A. (2007) Chapter 6 Zeolite membranes - synthesis, characterization and application, Stud. Surf. Sci. Catal. 168, 181.

4 Lin Y.S., Kumakiri I., Nair B.N., Alsyouri H. (2002) Microporous inorganic membranes, Separ. Purif. Method. 32, 229.

5 Coronas J., Noble R.D., Falconer J.L. (1998) Ind. Eng. Chem. Res. 166, 37.

6 Mintova S., Valtchev V., Engstrom V., Schoeman B.J., Sterte J. (1997) Micropor. Mater. 11, 149.

7 Hedlund J., Sterte P.J., Anthonis M., Bons A.J., Carstensen B., Corcoran N., Cox D., Deckman H., De Gijnst W., de Moor P.P., Lai F., McHenry J., Mortier W., Reinoso J., Peters J. (2002) Micropor. Mesopor. Mater. 52, 179.

8 Lai Z., Bonillla G., Diaz, Nery J.G., Sujaiti K., Amat M.A., Kokkoli E., Terazaki O., Thompson R.W.I., Tsapatsis M., Vlachos D.G. (2003) Science 300, 456.

9 Kusakabe K., Kuroda T., Murata A., Morooka S. (1997) Ind. Eng. Chem. Res. 36, 649.

10 Kusakabe K., Kuroda T., Morooka S. (1998) J. Membrane Sci. 148, 13.

11 Kusakabe K., Kuroda T., Uchino K., Hasegawa Y., Morooka S. (1999) AIChE J. 45, 1220.

12 Clet G., Gora L., Nishiyama N., Jansen J.C., van Bekkum H., Maschmeyer T. (2001) Chem. Commun. 41.

13 Hedlund J., Jareman F., Bons A.-J., Anthonis M. (2003) J. Membrane Sci. 222, 163.

14 Gouzinis A., Tsapatsis M. (1998) Chem. Mater. 10, 2497.

15 Giroir-Fendler A., Peureux J., Mozzanega H., Dalmon J.-A. (1996) Stud. Surf. Sci. Catal. 101A, 127.

16 Giroir-Fendler A., Julbe A., Ramsay J.D.F., Dalmon J.A. (1995) WO9529751 patent, assigned to Centre National de la Rercherche Scientifique (CNRS).

17 Chau C., Sicard M., Le Dred R. (2002) EP1369167 patent, assigned to Institut Français du Pétrole (IFP).

18 Chau C., Prevost I., Dalmon J.-A., Miachon S. (2002) EP1230972 patent, assigned to Institut Français du Pétrole (IFP).

19 Alshebani A., Pera-Titus M., Schiestel Th., Landrivon E., Miachon S., Dalmon J.-A. (2008) Micropor. Mesopor. Mat. $115,197$.

20 Miachon S., Landrivon E., Aouine M., Sun Y., Kumakiri I., Li Y., Pachtová Prokopová O., Guilhaume N., Giroir-Fendler A., Mozzanega H., Dalmon J.-A. (2006) J. Membrane Sci. 281, 228.

21 Li Y., Pera-Titus M., Xiong G., Yang W., Landrivon E., Miachon S., Dalmon J.-A. (2008) J. Membrane Sci. 325, 973.

22 Miachon S., Kumakiri I., Ciavarella P., van Dyk L., Fiaty K., Schurman Y., Dalmon J.-A. (2007) J. Membrane Sci. 298, 71.

23 Uzio D., Peureux J., Giroir-Fendler A., Dalmon J.A., Ramsay J.D.F. (1994) Stud. Surf. Sci. Catal. 87, 411.

24 Dong J., Lin Y.S., Hu M.Z.-C., Peascoe R.A., Paysant E.A. (2000) Micropor. Mesopor. Mat. 34, 241.

25 Daramola M.O., Burger A.J., Pera-Titus M., Giroir-Fendler A., Lorenzen L. (2009) J. Membrane Sci. (in press).

26 van Dyk L., Lorentzen L., Miachon S., Dalmon J.-A. (2005) Catal.Today 104, 274. 
27 Camus O., Perera S., Crittenden B., Delft Y.C.V., Dick F., Meyerb P., Pex P.A.C., Kumakiri I., Miachon S., Dalmon J.-A., Tennison S., Chanaud Ph. (2007) AIChE J. 52, 2055.

28 Ciavarella P., Casanave D., Moueddeb H., Miachon S., Fiaty K., Dalmon J.-A. (2001) Catal.Today 67, 177.

29 Ciavarella P., Moueddeb H., Miachon S., Fiaty K., Dalmon J.-A. (2000) Catal. Today 56, 253.

30 Miachon S., Mazuy A., Dalmon J.-A. (2000) Stud. Surf. Sci. Catal. 130, 2693.

31 Hamad B., Alshebani A., Pera-Titus M., Albela B., Bonneviot, Miachon S., Dalmon J.-A., (2008) Micropor. Mesopor. Mat. 115, L.40.

32 Soria R., Chanaud P. (2000) WO0033848, assigned to Société des Céramiques Techniques.
33 Alshebani A., Pera-Titus M., Yeung K.L., Miachon S., Dalmon J.-A. (2008) J. Membrane Sci.314, 143.

34 Millot B., Methivier A., Jobic H., Moueddeb H., Dalmon J.A. (2000) Micropor. Mesopor. Mat.38, 1.

35 Tuan V.A., Noble R.D., Falconner J.L. (2000) AIChE J. 46, 1201.

36 Mori N., Tomita T. (2008) Micropor. Mesopor. Mat. 112, 88.

37 Cheng Z., Gao E., Wan H. (2004) Chem. Commun. 1718.

Final manuscript received in May 2009

Published online in October 2009 